\title{
IMPERCEPTION FOR THE POSITION OF THE EYELIDS ON ONE SIDE
}

\author{
BY
}

\section{H. RUBINSTEIN}

(RECEIVED 11TH NOVEMBer, 1941)

\section{Introduction}

THE concept of the body schema in its present form originated from the investigations of Head and Holmes (1911-12) into sensory disturbances from cerebral lesions. They showed that appreciation of posture and passive movement requires a " standard against which all subsequent changes of posture are measured before they enter consciousness." For this fundamental standard they introduced the term schema or postural model of the body. They came to postulate a similar schema for the localization of stimuli applied to the body surface. These schemata they supposed to be formed by the past sensory impressions.

Claude (1909) assumed that mistakes in localization and estimation of posture can be caused by the disturbance of certain " mnestic centres for the topo- and kinæsthetic impressions and for the representations of the different parts of the body." Jones (1910) suggested an amnestic disturbance of the association between the sensory perceptions and the "autosomatognostic group of memory feelings" for his cases of allochiria. Pick, who had spoken of "spatial images of the body" (1908), adopted the term schema and stated that these schemata together with the optic image of the body are the essential framework for the consciousness of the body (1915). Earlier theories (Hartmann, Mach, Wernicke, Wundt) of the knowledge one has of one's own body have been summarized by Zingerle (1913). Schilder $(1923,1935)$ extended the concepts of Head and Holmes and of Pick. His " body schema " (or " body image") is a complex built up by many somatic factors, among which the postural, kinæsthetic and tactile, as well as the optic and vestibular impressions are the most significant. The body schema contains the representations of the different parts of the body and their spatial relations to each other.

The idea of the body schema has proved indispensable for the understanding of a variety of neurological and psychopathological conditions. In this paper it is proposed to deal with the group of body schema disorders that is most widely known as "anosognosia." This term was originally introduced by Babinski (1914) for cases of left hemiplegia who were completely unaware of and even denied the paralysis, no matter how often one had tried to convince 
them of the defect. Babinski's patients seemed to have altogether forgotten the paralysed limbs. F. Müller (1892), Pick (1894), and Anton (1896, 1899) had been the first authors to draw attention to cases of hemiplegia with imperception for the motor loss. The term "Anton's symptom " was used for unawareness of hemiplegia as well as for unawareness of cortical blindness or deafness. The term anosognosia applies only to imperception of hemiplegia, although it could be taken to imply lack of recognition of disease in general. A great number of cases has since become known. The many different interpretations and classifications may justify an attempt to define the main characteristics of the condition as reported in the literature.

\section{Imperception for One Half of the Body}

It has often been assumed that the unawareness of the paralysis and the lack of attention for the paralysed side are due to affective reasons. The conscious or unconscious tendency to forget or minimize the disability was believed to account for anosognosia and amnesia for the half of the body involved. But it has become increasingly evident that the disappearance of the affected side from the patient's consciousness is the fundamental disorder and is the immediate result of the cerebral lesion. The patient does not kriow that he is paralysed, because he has no knowledge of one half of his body. Only secondarily do psychological processes, such as repression and projection, enter into the formation of the symptom. "The psychological factor determines the final shape of the imperception of part of the body" (Schilder, 1935). In the majority of these cases there is a more or less pronounced hemihypoæsthesia which could be taken to explain the condition, if on the other hand there were not a great number of cases that do not show any appreciable sensory impairment. That a patient does not notice his paralysis and does not show any interest in the paralysed side as a whole can therefore only be attributed to a disorder of the body schema. Some of the patients who appear to overlook and never spontaneously use one side of the body are not even paralysed. This was first described by Bruns (1897). Oppenheim (1913) reported a case of right parieto-occipital tumour with apparent hemiparalysis and hypoæsthesia, where the presumed motor and sensory loss vanished when the patient's attention was stimulated. Such cases, showing amnesia for one side without there being any real disability, provide definite proof that in cerebral lesions the disappearance of one half of the body from consciousness is not the result of a repressive tendency. Schilder speaks of "organic repression." It may be less ambiguous to state that these are instances of an organic lesion and mechanism giving results similar to those of a psychological process. This organic counterpart to repression shows how close is the analogy between psycho-analytic concepts and biological facts.

Among the cases of one-sided body schema disorder one can distinguish a class that does not exhibit anosognosia in its stricter sense. Instead of ignoring the paralysis and the affected side of the body, these patients complain that they have lost the arm or the leg. Some observers, e.g. Stockert $(1934,1936)$, have 
assumed an important difference between this class and true anosognosia, maintaining that these patients are conscious of their defect. Closer scrutiny, however, reveals that this consciousness is but a very limited one. Such patients may at times be aware of the paralysis, but for the most part they do not show full insight into the cause of the disability. They have only a vague feeling of a disturbance which they attribute to a complete loss of the limbs. It seems that the affected half of the body does not as completely escape their attention as in cases of anosognosia; but knowledge of that side is grossly impaired and distorted. One is therefore justified in assuming that the difference between these two types of body schema disorder for one side is a difference only of degree. This opinion finds support in the patient whose anosognosia changes into, or alternates with, the feeling that his limbs are absent. Such a development is shown in cases reported by Ehrenwald (1931), Hagen and Ives (1937). Moreover, when patients belonging to either type are made to touch or view the affected half of the body, exactly the same reaction may be elicited: they declare the paralysed limbs are not their own, but someone else's arm or leg.

These facts argue with equal strength against the distinction made on different grounds by Nielsen (1938). This author maintains that in anosognosia the patient has forgotten only the paralysis, not the paralysed side as a whole, whereas "delusion of absence of the limbs" is to be considered as a severe form of amnesia for one half of the body. As early as 1918, in the discussion that followed Babinski's second report on cases of anosognosia, it was stated by Pierre Marie that this symptom is not an independent phenomenon, but belongs to the group of cases who have no idea of the existence of the paralysed half of the body.

The disturbance of the schema of one half of the body is the cause of anosognosia as well as of feeling of absence of one side. The best term for this body schema disorder seems to ke the one used by Schilder (1935): imperception for one half of the bcdy. The term anosognosia ought to be restricted to cases where the imperception results in unawareness of the hemiplegia. The other main type of imperception for one side is the feeling of absence of the limbs. This merely descriptive term is to be preferred to "delusion of absence." It will be shown later that only part of the symptom can be called a delusion.

\section{Hemiplegia with Phantom Limb}

The foregoing remarks are intended to show that there is no essential difference between unawareness of hemiplegia and feeling of absence of one half of the body. There seems, on the other hand, to be a fundamental distinction between the two types of imperception for one side and the cases of hemiplegia with a phantom limb. Imperception for one half of the body is the expression of a disorder of the body schema. The patients may in addition show loss of sensation, but this is not an essential. In the case of anosognosia patients ignore the paralysis believing they are able to move the limbs, but they have not the vivid impression of a phantom limb. The latter phenomenon is 
the expression of the persistence of the body schema, which is merely cut off from the periphery either by actual loss of a limb or by loss of sensation. Thus the body schema remains fixed according to the former state of the body. All cases of hemiplegia with phantom limb show more or less complete anæsthesia. Loss of sensation, especially of the postural sense, is an essential condition for the development of a phantom limb. It explains the phantoms in peripheral nerve lesions (Head; Lurje, 1936; Riddoch, 1937); in lesions of a nerve plexus (Mayer-Gross, 1929), in affections of the posterior roots and columns (Riddoch, 1937), in complete division of the spinal cord (Riddoch, 1917; Stein, 1929; Lhermitte and Tchehrazi, 1937), as well as in certain cases of hemiplegia (Pinéas, 1932).

Cases of hemiplegia with phantom limb are sometimes mistaken for cases of anosognosia, and vice versa. The difference is most obvious in the patient's attitude towards the affected side. The hemiplegic with a phantom limb may at times believe in its reality and forget his defect, but he will always try to make sure by touching or looking at his paralysed arm or leg. He will thus recognize the unreality of the phantom sensation. The anosognostic patient, who has lost all knowledge of the affected half of the body, will not attempt to investigate and may even refuse to look at the paralysed side. He remains unaware of the motor defect and maintains that he can move the limbs, although he never actually tries to move them. When asked to use the paretic arm or leg, he will either move the corresponding limb on the other side or altogether ignore the request. The patient with the phantom limb will sometimes attempt to use it. He then behaves as if he had not lost his limb or its motility. The anosognostic patient, on the other hand, behaves as if the affected limbs had been amputated.

While a sharp distinction is drawn between anosognosia and the phantom limb, it is not intended to deny that the two phenomena show certain analogies. But this applies only to later stages in their development. The gradual involution of the phantom limb follows modifications of the body schema which eventually adapts itself to the new situation. In some cases of anosognosia, e.g. in the first of the two cases described by Pötzl in 1924, the schema of the paralysed side appears to undergo restitution to a certain extent, which leads to phantom formation. These secondary developments do not, however, contradict the view that the phantom limb results from and is evidence for the persistence of the body schema, whereas anosognosia follows its primary reduction.

No attempt is here made to discuss more fully the pathogenesis of the phantom limb and in particular the question of the importance of peripheral sensory stimuli.

The following cases show a symptom that enters into the syndrome of imperception for one half of the body. 


\section{Case Histories}

Case 1.-R. F., a man aged 55, admitted to hospital on 31st August, 1937. He had been suffering from headaches and paræsthesias in the left hand for three months. One month before admission a left facial palsy had been noticed for the first time. Subsequently he developed headaches localized to the right temple, repeated vomiting, weakness of the left leg.

On admission: Bilateral papillœdema. No hemianopia. Left corneal reflex absent. Left supranuclear facial paresis including the orbicularis oculi. Deviation of tongue to the left. Moderate left hemiparesis with hypotonus. Cutaneous sensation: marked hypoæsthesia for touch, pain, and temperature on the left side of the body including the face. It was remarkable that the patient failed to appreciate the difference in his perception of stimuli applied to the two sides of his body even though on the left he sometimes mistook hot for cold, and vice versa. He was able to indicate the directions of passive movements at all joints, but there was some leftsided ataxia. Left abdominal reflexes absent. Left knee jerk slightly exaggerated. Both plantars flexor.

7th September. Ventriculography: Attempt to reach the right ventricle unsuccessful; the left lateral ventricle appeared well filled with air, dilated and displaced to the left. The subsequent operation (Prof. Schönbauer) revealed a cystic tumour, containing about 50 c.c. of fluid, extending deeply into the white matter of the right central convolutions and the adjoining parts of the right parietal lobe. The tumour was removed as far as practicable. Histological report: mixed spindle- and roundcelled sarcoma.

A few hours after the operation the left hemiparesis became complete. On 24th September the following changes were noted: Papillœedema receding. Complete flaccid paralysis of the left side. Almost complete left hemianæsthesia for all forms of cutaneous sensation. From time to time the patient would recognize a pin prick on the face as such, or appreciate both hot and cold stimuli applied to the trunk as " burning hot." Throughout examination he did not show any appreciation of sensory disturbance. Even when his attention was specially drawn to the fact that there was a marked difference in his reactions to stimuli applied to the left side as compared with the right, he would not agree. The sense of posture and passive movement was abolished in all joints of the left arm and leg, with the exception of shoulder and hip joint where it was merely diminished. Left astereognosis.

The symptom to which it is particularly intended to draw attention in this paper was noticed in connection with the left facial palsy, which had after the operation become complete in the lower branch. When the patient was asked to shut his eyes, he could do so for a moment; but immediately afterwards the left eye opened again, whereas the right eye remained shut. When the patient was told to make an effort to keep the left eye shut, he was not only unable to do so, but it also appeared that he did not know that his left eye was open. He said: "But both my eyes are shut," although the left eye was wide open. The following conversation then took place: (Don't you see me?) “No, I don't see you." The patient was directly facing the examiner. (Look more closely!) "Yes, now I can see you." (Are your eyes open or shut?) "My eyes are shut." (Then how are you able to see me?) "I can see you, but my eyes are both shut." (How is this possible?) "Well . . . perhaps the left one is not completely shut, just a little bit open because of the facial palsy." This latter remark is explained by the patient's knowledge of medical terms and suggests that his intellectual powers were intact. It obviously was the result of a compromise between two conflicting sensations, the optic perception and the feeling that both eyes were completely shut.

The patient was then asked to open his eyes, whereupon he opened the right eye, which so far he had kept tightly shut. He now had the sensation that both eyes 
were open. When the patient was asked to shut his eyes again, there followed the same sequence of reactions as at the first attempt.

On the other hand, when the eyes were passively closed and the left upper lid was subsequently allowed to open, the patient said at once that he could see and that the left eye was open whereas the right was kept shut by the examiner.

Passive movements of all parts of the face, including the left eyelids, were noticed, their directions recognized.

In the course of the next few months the paralysis and the disturbance of joint sense gradually receded, but there was still marked ataxia. When the patient made his first attempts to walk, he never knew where the left leg was, or when it was time for the left leg to move forward. He could walk without interruption only if constantly told when to move the left leg. Similarly, he did not use the left arm unless especially asked to do so. When he intended to keep his eyes shut, he always had the feeling that both eyes were closed, although the paresis of the left orbicularis oculi was unchanged. There was only this difference compared with his first reactions that he no longer said he could not see when his left eye was wide open.

In February 1938, when the patient left the hospital, the left facial palsy had so far improved that the eyelids covered part of the cornea. He still did not perceive that he could not shut his left eye completely. The movements of the left arm and leg were much improved in the proximal joints, and so were co-ordination and joint sense. The disorder of the cutaneous sensation, however, was only very slightly improved on the whole left side.

Case 2.-J. W., a man aged 45, admitted to hospital on 7th December, 1937, suffering from lobar pneumonia. On 2nd January, 1938, about a fortnight after subsidence of the pneumonia, the temperature rose again. Rhinological and X-ray examination revealed an infection of the right paranasal sinuses.

On 4th January the patient collapsed suddenly; when he had regained consciousness, it was found that he was completely paralysed on his left side. Left ankle clonus. Extensor plantar response on both sides, more marked on the left. Sense of posture and passive movement abolished on the left. Cutaneous sensation: complete anæsthesia on the whole left side of the body including the face (left corneal reflex absent). From questions designed to elicit his appreciation of the sensory difference between left and right it appeared that the left-sided sensory loss was not always noticed by the patient. Fundi normal. Left homonymous hemianopia. Complete paralysis of the left lower face. The power of the left orbicularis oculi was diminished so that the left eyelids gradually opened to a half-way position, whereas the right eye remained shut.

At this stage the patient was asked whether both eyes were shut. He said they were, and to the next question said he could not see anything. When then pressed, he admitted that he could see. (How can you see with your eyes shut?) "Perhaps one of my eyes is not completely shut." (Which eye is open?) "The right one." Asked to point to the open eye, the patient pointed to the closed right eye. Asked to touch the right eye, he did so and realized only now that the left eye was the open one.

It was evident that this mistake was the consequence of the left hemianopia. The remaining right field of vision was referred to the right eye, as is so frequently found in cases of hemianopia. The unusual symptom was the persistent feeling that both eyes were shut while in fact the left was open. Only when he realized that he could see did he conclude that one eye was partly open. This symptom could be demonstrated at all subsequent examinations until, with the gradual improvement of the hemiplegia, the supranuclear facial palsy had receded.

4th January. Blood showed leucocytosis with neutrophilia. C.S.F. clear, globulin tests slightly positive, no increase of cells. The diagnosis of metastatic abscess was made.

2nd March. Encephalography revealed marked dilatation of the right lateral 
ventricle and the sub-arachnoid space on the right side, without displacement of the ventricular system.

Case 3.-G. P., a man aged 40, admitted to hospital on 26th July, 1938. Some four years ago, while travelling in a bus that crashed into a tree, he had been hurled against the seat in front of his. No visible injury. He went to bed because of "shock." Nine days after the accident, while in bed, he suddenly felt his left arm and face become weak and numb. This attack lasted for about an hour. Frequent attacks of right hemicrania followed and had persisted. Two months before admission he had two attacks of twitching of the left side of the face at two hours' interval, followed by transient facial paresis. One month later, on awakenıng, he noticed weakness of his left arm which lasted only two hours. One week before admission he developed a severe headache, and his left arm and leg became weak and numb. Two hours later facial twitching appeared, followed by paresis. The hemiparesis now persisted. The patient complained of headaches and repeated vomiting.

On admission it was noticed that he was unable to keep his eyes shut for more than a few seconds, which was then attributed to lack of concentration. Optic discs: both nasal halves blurred (no obvious papillœdema). No hemianopia. Left facial paralysis of supranuclear type. Marked paresis of the left limbs, more pronounced in the arm, with some spasticity. Cutaneous sensation normal. Joint sense slightly diminished in the left toes. Left abdominals absent. Tendon reflexes increased on the left side. Plantars flexor on both sides.

Lumbar puncture: C.S.F. clear and colourless, with flocculent coagulum. Cells: 35 per c.mm. Total protein 0.04 per cent. Pandy weakly positive, Nonne-Apelt negative. Wassermann reaction negative. X-ray of skull negative.

11th August. The patient still had difficulty in keeping his eyes shut for more than a few seconds. It now appeared that this was due to the left facial palsy which involved the upper branch, though to a lesser degree than the lower: when urged to try hard to keep his eyes shut, he succeeded in keeping his right eye shut, whereas the left upper lid rose slowly until the left eye was wide open. Asked at this stage whether his eyes were closed, the patient's answer was "yes." $\mathrm{He}$ did not deny that he could see, but he added that he still felt that both eyes were shut. Left corneal reflex absent. No impairment of the cutaneous sensation of the face. Temperature sense slightly diminished over the left foot. Joint sense diminished in the left fingers and toes.

16th August. Operation (Mr. Harvey Jackson): Right parietal osteoplastic flap. No tumour found. ? Cortical atrophy.

8th September. Ventriculography (Mr. F. H. Masina): Low grade symmetrical hydrocephalus. Ventricular fluid: L. and R. clear and colourless. No cells seen. Globulin tests negative. Protein less than 0.01 per cent.

After the operation the patient was able to keep both eyes closed, although there was still some weakness of the left orbicularis oculi. The other signs of the hemiplegia were also gradually receding. The patient was discharged on 23rd September.

Case 4.-H. C., a woman aged 63 . This patient was admitted to the Northumberland Mental Hospital on 6th December, 1935, after having been detained in private mental hospitals under certificate from the age of 39. She had fixed delusions of persecution, and auditory as well as visual hallucinations. Her chief complaint was that snakes and other reptiles were continually assailing and biting her. Her intellectual powers were in no way impaired.

On 12th April, 1940, she had a cerebral hæmorrhage with a few seconds' loss of consciousness. The left arm and leg were completely paralysed. So was the left lower face; she was unable to keep her left eye closed and could not wrinkle the left half of her forehead to the same extent as the right. Left homonymous hemianopia. Left corneal reflex absent. Complete left-sided anæsthesia, including the face. Sense of posture and passive movement abolished in all joints of the left side. Passive 
movements of the left eyelids were not perceived. Left abdominals absent. Left tendon reflexes diminished. Extensor plantar response on the left side.

When the patient had regained full consciousness, she did not know what had happened to her. Asked whether she could move her left arm, she first said "yes." Asked for her left hand, she moved her right hand to the left shoulder and then appeared to search for her left hand at the level of the elbow. When she eventually got hold of her left hand, she asked: "Is it here?" She now realized she could not move it.

When she intended to keep her eyes shut, she did not notice that the left upper lid was gradually rising, leaving the eye almost completely uncovered. Asked whether she could see the people around her, she first denied it; but when the test was repeated later in the day, she admitted that she could see although the feeling persisted that both eyes were shut.

On the next day the patient said: "I cannot believe I have an arm. Have you taken it off? I had a terrible shock this morning when I touched my left hand; I thought it was the head of a reptile." Asked where her left arm was, she said: "I don't know. Where is it? I don't feel it." When she had found her left hand by groping along the arm from the shoulder downwards, she exclaimed: "That is someone else's hand. Whose is it? It is not mine. It is a reptile." Only by comparing closely the left thumb with the right did she recognize the left hand as her own. She still said: "It does not feel as if it were mine. It is dead. Is it really my own arm? What has happened to it?"

During the following days she began to realize that she had been paralysed by a stroke and that it was difficult for her to keep the left eye shut. She complained repeatedly that her left arm, and to a lesser degree her left leg, felt dead and queer. " They must be my own because they hang on to my body, but they feel strange." At times, mainly at night or in the early morning, she would tell a nurse that a corpse was lying in her bed at the left side, or that " a poor dead devil's arm " had been put in place of her own.

The left hemianopia had receded completely, but the patient did not pay much attention to objects in her left visual field. At the stage when the left eye no longer opened spontaneously, it could still be shown by separating the lids with the finger that she did not perceive their position. When the left eye had thus been opened, she would either say: "Both my eyes are shut; I can see through the lids," or " The left eye feels as if it were shut, but I know it must be open because I can see and I definitely feel that the right eye is shut." Conversely, when her eyes were open and the left was closed by the examiner, she still believed both eyes to be open.

About a fortnight after the apoplexy motor and sensory function began to improve. The return of cutaneous sensation was accompanied by mistakes in localization: on the left side most of the stimuli were felt nearer the median plane in the same segment; sometimes pin-pricks applied to the left side of the trunk were even referred to the right, close to the middle line, the disturbance thus approaching full alloæsthesia. Her left limbs still felt strange, but this disturbed her less. When making the first attempts to walk, she sometimes complained that she did not know the position of her left leg. She would then ask: "Where has it gone?" When her left eye was opened, she could tell at once that it was open; but she admitted that she knew this only because she could see. Confirmation was to be found in her continued inability to tell when the left eye was passively closed. The persistence of this symptom was the more striking as the cutaneous and deep sensation of the face was then much improved: the patient could feel the examiner's finger on her left eyelids and could even at times indicate the direction of passive movements of the lids. 


\section{Discussion}

In these four cases of left hemiplegia with involvement of the orbicularis oculi it was found that the patients had no knowledge of their inability to keep the left eye closed. When they tried to keep both eyes shut, and the left eye had opened again whereas the right eye remained shut, they had the feeling that both eyes were shut. In three of the four cases the patients even denied that they could see. Only when questioned more closely, or after repeated experiments, did they admit that they could see, although they retained the impression that the left eye was as completely shut as the right. They then tried to explain the paradox by assuming that the left eye was not quite shut, " just a little bit open," or in one instance by saying, "I can see through the lids." The subjective feeling that both eyes were shut persisted even later on when the patients had become aware of the paresis of the left eyelids. Further proof of the fact that the described symptom contains more than unawareness of a motor defect was to be found in case 4. When this patient had regained sufficient power to keep her left eye shut, it could be opened by the examiner without her noticing that the eye was now open. Moreover, when her eyes were open and the left was passively closed, she thought both eyes were still open. The question whether both eyes were open or shut was always answered in terms of the right eye. This makes it clear that the essence of the symptom is an imperception for the position of the left eyelids, which results in unawareness of a motor defect, but may be present independent of whether there is paralysis or not.

When we come to analyse this disturbance, we have to note that all cases showed varying degrees of sensory impairment. The left corneal reflex was absent in all four cases. But case 3 had no further sensory loss in the face. Case 4 remained unaware of the position of the left eyelids even when all forms of facial sensation were improved. In case 1 the left-sided anæsthesia was almost complete, but there was no loss of sensation for passive movements of the eyelids. These facts lead to the conclusion that the inability to appreciate the position of the lids is essentially independent of the state of cutaneous and deep sensation.

In three of the four cases the sensory examination by itself revealed, in addition to the more or less marked loss of sensation, signs of disturbance at a higher level. The first patient did not notice his severe hypoæsthesia, which he persistently refused to acknowledge. Case 2 showed a similar, though less constant, anosognosia for the sensory loss. In case 4 the displacement of sensory stimuli towards the right side of the body, sometimes tantamount to alloæsthesia, was very similar to mistakes in localization described by Kramer (1915), Van Bogaert (1934), Nielsen and Sult, Jr. (1939), in cases of imperception for the left side due to disorder of the body schema. It thus appears that ignorance of whether the left eye is open or shut belongs to the larger syndrome of imperception for the whole left side of the body. In case 3 this disorder of the body schema was limited to the eyelids; no other sign of disorientation for the left side could be found. Cases 1 and 2 show the symptom of the 
eyelids together with imperception of the left hemianæsthesia. These two patients had no anosognosia for the hemiplegia. Amnesia for the left limbs, however, was found in case 1: even when the paralysis had to a certain extent receded, the patient did not spontaneously use his left arm or leg. In case 4 imperception for the position of the left eyelids was part of a complete left-sided imperception in the form of feeling of absence of the limbs. The patient said her left extremities felt queer, as if they were not her own; she thought she had lost her left arm, that it was someone else's arm, the arm of a corpse, or even that it was a reptile. This latter illusion fitted so closely into the delusions the patient had been voicing for many years, that it might have been attributed to her mental disorder. But the snakes and other reptiles by which she felt herself tormented had never before been identified with parts of her own body. Further, exactly the same illusion has been observed in patients with imperception for one half of the body who were not suffering from a psychosis. Pötzl (1924) describes the case of an anosognostic patient who said his paralysed arm belonged to somebody else; he would at times look at his left arm with the expression of utmost horror, exclaiming a snake was creeping towards him. Ehrenwald (1931) reported a case of left hemiplegia who, after a period of anosognosia, complained that he had lost his left arm and that it had been replaced by a snake. Delusions that the affected limbs belong to someone else, or that a corpse, stranger, or double lies at the patient's side, are frequently met in cases of imperception for one half of the body. The common feature of all these delusions is the projection of the affected half of the body into the outside world. They are secondary productions, resulting from the patients' feeling of absence of one side and from their inability to recognize their limbs as their own. This agnosia or imperception for one half of the body is the primary symptom; it is the immediate consequence of the cerebral lesion, the expression of organic disorder of the body schema.

Almost identical symptoms have been observed in psychogenic disorders, e.g. in a case of hysterical hemianæsthesia (Bernheim, 1893) and in cases of hysterical dyschiria (Jones, 1907 and 1910). Schilder $(1923,1935)$ and Ehrenwald (1931) have discussed the relationship between depersonalization and hypochondria on the one hand, and organic disturbances of the body schema on the other. All these conditions show that the function of the body schema can be disturbed by psychogenic processes as well as by cerebral lesions. The resulting symptoms, and probably also the final mechanisms of their production, may in many cases be the same for both psychogenic and organic disorder.

Some authors have stressed the importance of hemianopia and conjugate deviation in the development of imperception for one side of the body. None of the four cases had deviation of either head or eyes. In one of the two cases with left homonymous hemianopia the visual field became normal a few days after the apoplexy (Case 4). It then appeared that the patient paid less attention to objects in her left visual field. This symptom has been noticed in a number of similar cases who had not previously been hemianopic. It seems to be the consequence rather than the cause of the imperception for the left half of the body, which in some cases leads to more or less complete im- 
perception for the left half of the external space. Homonymous hemianopia and conjugate deviation towards the normal side do, of course, facilitate imperception for the paralysed side, but they do not appear to be essentials for this condition. A hemianopia may, however, modify the symptom of imperception for the eyelid position, as shown in case 2 .

Imperception of paresis of the eyelids, and of their position, due to disturbance of the body schema has not hitherto been reported in the literature. Hofmeister and Meyer (1906) described a case of sarcoma of the right Gasserian ganglion who did not know whether the right eye was open or shut. This was fully explained by anæsthesia of the face combined with complete blindness of the right eye due to secondary optic atrophy. The striking point in the cases reported in this paper was that the patients had no knowledge of the position of their eyelids on one side although they were not blind in that eye. Three of them went so far as to deny that they could see: the feeling that the left eye remained shut led at first to a suppression of its visual perception. This is analogous to the not uncommon finding that a patient with imperception for one half of the body does not know where his arm is, and maintains he has lost it, even when the arm lies in the centre of the patient's visual field (Schuster, 1936). Golman (1935) observed in some cases of infranuclear facial paralysis that the patients were unaware of the motor defect until attention was drawn to it. They all showed disturbance of proprioceptive facial sensation. They had illusions of movement of the paralysed muscles. Golman described this condition as anosognosia. Anosognosia, however, is not the right term for such cases. It is characteristic that the unawareness of the paralysis did not persist after the patients had been told of the motor loss. This type of unawareness of motor defect with illusions of movement corresponds to the transient imperception for peripheral paralysis, hemiplegia, or amputation, in cases with phantom limbs. The essential conditions are the same in all these cases: loss of a limb, or of motility and sensation in one part of the body, the cerebral mechanism that secures the body schema being intact.

In the cases described in this paper, where the unawareness of the eyelid paresis appeared to be caused by a disorder of the body schema, there were no phantom sensations, no motor illusions. The patients had the impression that the left eye remained shut, because they had intended to shut both eyes, and because they correctly perceived the right eye as shut, whereas they had no perception for the actual position of the left lids. For the same reasons do patients with unawareness of hemiplegia more readily believe that they are performing the required movements with the paralysed arm when they are asked to move both arms simultaneously (Pinéas, 1926). The anosognosia can only be maintained because of the underlying imperception for the affected half of the body. Unawareness of paralysis and imperception for one side were in one of the four cases restricted to the eyelids, and in the others there most pronounced. The patients could not tell whether the left eye was open or shut, because they had no knowledge of the position of the left eyelids. Mills (1910) expressed the opinion that the postural sense is not as highly developed for the muscles innervated by the facial nerve as for those of the limbs. His 
argument was based on the facts that the sense of position is both a muscle and a joint sense, that the recognition of position of a limb is largely dependent upon impressions received from joints, and that the facial muscles, except, of course, those of mastication, do not perform movements about a joint. Mills concluded that these movements " are probably not to any large extent dependent for their proper performance upon the postural sense, at any rate not to the same extent as joint movements." It is obvious that the movements of the eyelids do not require a precise sense of position. Considering the importance of the postural and kinæsthetic impressions for the development of the body schema, one may well assume that the eyelids are less firmly represented in the schema than other parts of the body. This would explain that imperception for the position of the eyelids on one side can be the most pronounced, and in some cases, as in case 3, the only sign of imperception for one half of the body.

The cases reported in this paper do not lend themselves to attempts at exact localization, for none was verified by autopsy. The full extent of the tumour in case 1 could not be ascertained at the operation; pathology and localization of the lesions in the other three cases can only be surmised. But all the verified cases of one-sided disorder of the body schema show more or less circumscribed lesions of the parietal lobe. The view that anosognosia can be caused by lesions of the corpus callosum has not been substantiated. Cases used to support this localization show lesions extending into the parietal lobe. Some authors place the main stress on lesions in or close to the thalamus, others on lesions of the parietal cortex in the region of the interparietal sulcus and the angular and supramarginal gyri. In the two cases reported by Pötzl in 1924 there were lesions both in the thalamus and at the bottom of the interparietal sulcus. Schuster $(1936,1937)$, in his "Contributions to the Pathology of the Thalamus," came to the conclusion that the thalamo-parietal system is to be considered as a physiological unity. His view is that a lesion at any point between the thalamus and the parietal cortex can give rise to disorder of the body schema. The body schema disturbance described in this paper can therefore be safely attributed to parietal lesions, a localization that is corroborated by the other clinical symptoms in the four cases and by the site of the tumour in case 1 .

These were all cases of imperception for the position of the left eyelids. So also the syndrome of imperception for the complete half of the body has in the great majority of cases been found in left hemiplegia. Some authors tried to explain this fact by attributing to the right hemisphere a leading role with regard to the body schema. Others adopted the view expressed by Hauptmann (1928) that the left hemisphere is of such predominant importance for the body schema that any lesion preventing the sensory impressions from the left half of the body from reaching the left cerebral cortex by way of the corpus callosum will cause anosognosia. But by now a number of cases with imperception for the right side, without any indication of left-handedness, have become known, which warrants the conclusion that the organic substrate of the schema for either half of the body is localized in the contralateral hemi- 
sphere. In this respect at least the right hemisphere appears to be the equal of the left. The knowledge of the spatial relations of the different parts of the body to each other and to the body as a whole is lost in bilateral lesions of the parietal lobes (Pick's autotopagnosia). Only the highly specialized functions of the body schema are predominantly vested in the major hemisphere: Gerstmann's finger agnosia and confusion between right and left are caused by lesions at the border of the angular gyrus and the second occipital convolution of the left hemisphere.

A plausible explanation for the prevalence of imperception for the left side has been suggested by Schilder (1935). He points out that there is a physiological tendency in right-handed persons to neglect the left half of the body, and argues that most focal lesions of the left hemisphere will not have the effect of overcoming this tendency, whereas focal lesions of the right hemisphere " added to the physiological tendency to neglect the left side will provoke the picture of non-perception of the left side of the body." In most of the larger lesions of the left hemisphere the aphasia would make it difficult to detect the body schema disorder. A similar opinion had been expressed by Hoff and Pötzl (1931).

The hypothesis that the left side is less firmly represented in the body schema than the right may be supported by an observation made by Tournay (1922). This author found that the infant begins to look at and use the right hand at the age of about four months: only about a month later does it pay similar attention to the left hand. This observation which seems to suggest that in right-handers the knowledge of the left side develops later than that of the right has not yet been verified on a larger scale. It is obvious, however, that in later life far more impressions of all kinds come from the right than from the left hand and arm. As these impressions are the elements by which the body schema is built up, the schema of the left half of the body will never be as well established and will therefore be more easily affected by pathological processes than the schema of the right side.

These considerations do not apply to the eyelids. The movements of the eyelids are exquisitely bilateral and symmetrical. If one eye is shut by itself, the tendency to shut the other eye simultaneously is always revealed by a slight contraction of the orbicularis, and in forced shutting by compensatory action of the frontalis. There is no unilateral dominance with regard to the eyelids. It is therefore possible that imperception limited to the lids may be found in left hemisphere lesions that do not suffice to produce imperception for the whole right side. This remains to be seen, and would be mainly of theoretical interest, for in affections of the left parietal lobe there will be other localizing signs.

The symptom described in this paper may, however, be of some clinical value in affections of the right hemisphere. Nielsen (1938) says: "In the field of cerebral localization there has been great advance in the last 25 years, much of which is not of aid in lesions of the right hemisphere. The syndrome of amnesia or unconsciousness for the left limbs stands out as one of the few definite aids in diagnosis of lesions of the right parietal lobe." In one of the 
cases here reported the imperception for the position of the left eyelids was the only sign of body schema disorder. By revealing such a disorder it may in certain cases help to diagnose an affection of the right parietal lobe.

Unawareness of the one-sided sensory loss may have a similar value. Zingerle (1913) was the first to point out that the patient who is unaware of his hemiplegia ignores the hemihypoæsthesia as well. This was confirmed by Barkman (1925). Cases 1 and 2 of this paper showed anosognosia limited to the sensory loss. It is obvious that the latter can more easily escape consciousness than the paralysis. Isolated imperception for the hypoæsthesia seems to be another indicator of one-sided disorder of the body schema.

\section{Summary}

It is shown that unawareness of hemiplegia and feeling of absence of the limbs are closely related symptoms, and result from imperception for one half of the body.

A distinction is made between this disorder of the body schema and hemiplegia with phantom limb.

Four cases are described to illustrate a symptom that forms part of the syndrome of imperception for one half of the body: unawareness of whether one eye is open or shut, due to imperception for the position of the eyelids on the affected side.

The pathogenesis and value of this symptom are discussed.

The similarity between organic and psychogenic disturbance of the body schema is emphasized.

I wish to express my gratitude for permission to publish the case histories to Dr. H. Hoff, late Medical Director of the Neurological Department, Allgemeine Poliklinik, Vienna (cases 1 and 2); Dr. T. Grainger Stewart, Physician to the National Hospital, Queen Square, London (case 3); Dr. G. R. East, late Medical Superintendent of the Northumberland County Mental Hospital, Morpeth (case 4).

\section{REFERENCES}

Anton, G. (1896). Mitt. Ver. Arz. Steierm., No. 3.

(1899). Arch. Psychiat. Nervenkr., 32, 86.

Babinski, M. J. (1914). Rev. Neurol., 27, 845.

- (1918). Ibid., 34, 365.

Barkman, A. (1925). Acta med. Scand., 62, 235.

Bernheim, H. (1893). Brain, 16, 181.

Bruns, L. (1897). Festschr. Nietleben, p. 375.

Claude, H. (1909). Bull Soc. Méd. Hôp. Paris, 28, 89.

Ehrenwald, H. (1931). Nervenarzt, 4, 681.

Golman, S. (1935). Sovet. Nevropat., 4, 201 (Abst. Zbl. ges. Neurol. Psychiat., 78, 116).

Hagen, K. O. von, and Ives, E. R. (1937). Bull. Los Angeles Neurol. Soc., 2, 95.

Hauptmann (1928). Arch. Psychiat. Nervenkr., 82, 262.

Head, H., and Holmes, G. (1911-12). Brain, 34, 102.

Hoff, H., and Pötzl, O. (1931). Z. ges. Neurol. Psychiat., 137, 722.

Hofmeister and Meyer, E. (1906). Disch. Z. Nervenheilk., 30, 206.

Jones, E. (1907). Brain, 30, 490.

(1910). J. Psychol. Neurol., 15, 145.

Kramer, F. (1915). Neurol. Cbl., 34, 287.

Lhermitte, J., and Tchehrazi, E. (1937). Encéphale, 32/I, 1.

Lurje, S. (1936). Sovet. Nevropat., 5, 263 (Abst. Zbl. ges. Neurol. Psychiat., 81, 468). 
Marie, P. (1918). Discussion Babinski, Rev. Neurol., 34, 366.

Mayer-Gross, W. (1929). Nervenarzt, 2, 65.

Mills, Ch. K. (1910). J. nerv. ment. Dis., 37, 273.

Müller, F. (1892). Arch. Psychiat. Nervenkr., 24, 856.

Nielsen, J. M. (1938). Arch. Neurol. Psychiat. Chicago, 39, 536. (1938). Bull. Los Angeles Neurol. Soc., 3, 127.

Nielsen, J. M., and Sult, Jr., Ch. W. (1939). Ibid., 4, 69.

Oppenheim, H. (1913). Lehrbuch Nervenkrankh., Karger, Berlin, 6th edition, p. 889.

Pick, A. (1894). Prager Med. Wschr., quoted by Pick, Beiträge zur Patholog. Anatomie des Central-Nervensystems, Karger, Berlin, 1898, p. 173. (1908). Studien zur Hirnpathologie und Psychologie, Berlin, p. 11. (1915). Neurol. Cbl., 34, 257.

Pinéas, H. (1926). Dtsch. Z. Nervenheilk., 94, 238. (1932). Nervenarzt, 5, 233.

Pötzl, O. (1924). Z. ges. Neurol. Psychiat., 93, 117.

Riddoch, G. (1917). Brain, 40, 264. (1937). Encéphale, 32/I, 25.

Schilder, P. (1923). Das Körperschema, Springer, Berlin. (1935). The Image and Appearance of the Human Body, Psyche Monographs: No. 4, Kegan Paul, London.

Schuster, P. (1936). Arch. Psychiat. Nervenkr., 105, 358, 550. (1937). Ibid., 106, 13, 201.

Stein, J. von. (1929). Quoted by Mayer-Gross, W. (see above).

Stockert, F. G. von. (1934). Dtsch. Z. Nervenheilk., 134, 1. (1936). Wien klin. Wschr., 49, 806.

Tournay, A. (1922). Rev. Neurol., 38, 580.

Van Bogaert, L. (1934). Ann. méd.-psychol., 92/II, 519, 744.

Zingerle, H. (1913). Mschr. Psychiat. Neurol., 34, 13. 